\title{
Role of transcription factor acetylation in the regulation of metabolic homeostasis
}

\author{
Joo-Man Park ${ }^{1}$, Seong-Ho Jo ${ }^{1}$, Mi-Young Kim ${ }^{1}$, Tae-Hyun Kim ${ }^{1}$, Yong-Ho Ahn ${ }^{1,2 \bowtie}$ \\ ${ }^{1}$ Department of Biochemistry and Molecular Biology, Yonsei University College of Medicine, 50-1 Yonsei-ro, Seodaemun-gu, \\ Seoul 120-752, Republic of Korea \\ 2 Brain Korea 21 PLUS Project for Medical Sciences, Yonsei University College of Medicine, 50-1 Yonsei-ro, Seodaemun-gu, \\ Seoul 120-752, Republic of Korea \\ $\square$ Correspondence: yha111@yuhs.ac (Y.-H. Ahn)
}

Received July 9, 2015 Accepted July 24, 2015

\begin{abstract}
Post-translational modifications (PTMs) of transcription factors play a crucial role in regulating metabolic homeostasis. These modifications include phosphorylation, methylation, acetylation, ubiquitination, SUMOylation, and O-GIcNAcylation. Recent studies have shed light on the importance of lysine acetylation at nonhistone proteins including transcription factors. Acetylation of transcription factors affects subcellular distribution, DNA affinity, stability, transcriptional activity, and current investigations are aiming to further expand our understanding of the role of lysine acetylation of transcription factors. In this review, we summarize recent studies that provide new insights into the role of protein lysine-acetylation in the transcriptional regulation of metabolic homeostasis.
\end{abstract}

KEYWORDS metabolic homeostasis, transcription factor, post-translational modification, type 2 diabetes mellitus

\section{INTRODUCTION}

Chronic metabolic disorder has become a worldwide health problem, in parallel with the increasing incidence of obesity and type 2 diabetes mellitus (T2DM) (Chen et al., 2012). Metabolic syndrome is a disorder caused by abnormal energy utilization and storage (Zivkovic et al., 2007). The pathogenesis of metabolic syndrome involves both insulin resistance and $\beta$-cell dysfunction (Kahn et al., 2006). In the insulin-resistance state, the peripheral tissues do not respond to normal circulating concentrations of insulin due to abnormalities in metabolic control mechanisms (Perry et al.,
2014). Understanding molecular mechanism(s) of PTM may provide a novel background for develop drugs for antimetabolic syndrome.

In the adaptation of eukaryotic cells to internal and external stimuli, transcription factors act as critical mediators coordinately regulating biological processes (Francis et al., 2003). In most cases, these transcription factors exert their actions by directly binding to cognate consensus sequences of target genes ( $\mathrm{Li}$ et al., 2015). These transcription factors are subjected to post-translational modifications (PTMs) affecting their activity, stability, intracellular distribution, and interaction with other proteins (Nerlov, 2008). Types of PTMs include reversible acetylation, phosphorylation, SUMOylation, glycosylation, and ubiquitination (Meek and Anderson, 2009; Zhao et al., 2011). Recently, acetylation and deacetylation of histones and nonhistone proteins have been shown to be involved in the control of cellular energy metabolism (Kim et al., 2006; Guan and Xiong, 2011).

Protein acetylation on lysine residues is regulated by two types of enzymes, histone acetyltransferases (HATs) and histone deacetylases (HDACs). HATs transfer acetyl groups to lysine residues of the substrate proteins, while HDACs catalyze the reverse reaction (Haigis and Sinclair, 2010; Choudhary et al., 2014). HAT/HDAC families are responsible for the fine control of energy metabolism by regulating the transactivation of transcription factors.

Although many recent reviews have described the acetylation and deacetylation of nonhistone proteins, including transcription factors (Glozak et al., 2005; Wang et al., 2011; Choudhary et al., 2014), specific acetylation of the transcription factors associated with regulation of metabolic genes and its relevance to metabolic homeostasis have not been well described. In this review, we will limit our 
discussion to the relevance of acetylation of transcription factors (excluding nuclear receptors) involved in glucose and lipid metabolism.

\section{HATS AND HDACS}

\section{Introduction to HATs and HDACs}

In recent decades, acetylation of histones and nonhistone protein has been shown to be a ubiquitous phenomenon that occurs in eukaryotic cells (Vahid et al., 2015). The opposing activities of HATs and HDACs can modulate the activities of diverse transcription factors and regulatory proteins (Glozak et al., 2005; Wang, 2011). The effects of acetylation on various transcription factors are illustrated in Fig. 1. Historically, HATs have been divided into two types depending upon their cellular localization. Type A HATs acetylate both histones and nonhistone proteins in the nucleus. Type $B$ HATs, on the other hand, catalyze the acetylation of histones in the cytoplasm (Lee and Workman, 2007). Recently, some HATs have been shown to function within both the nucleus and cytoplasm and have even been shown to act in the form of multiple complexes (Kimura et al., 2005). Thus, the previously supported classification of HATs into these two groups has become outdated (Carrozza et al., 2003; Allis et al., 2007). At present, there are three major families of HATs: Gcn5-related N-acetyltransferases (GNATs), MYST proteins, and CAMP-response element-binding protein (CBP)/E1A-associated protein of $300 \mathrm{kDa}$ (p300) (Lee and Workman, 2007).

Acetylated proteins are deacetylated by HDACs. There are three classes of mammalian HDACs, which are classified based on their homology to their yeast counterparts. Recently, a fourth subfamily of HDACs was added based on
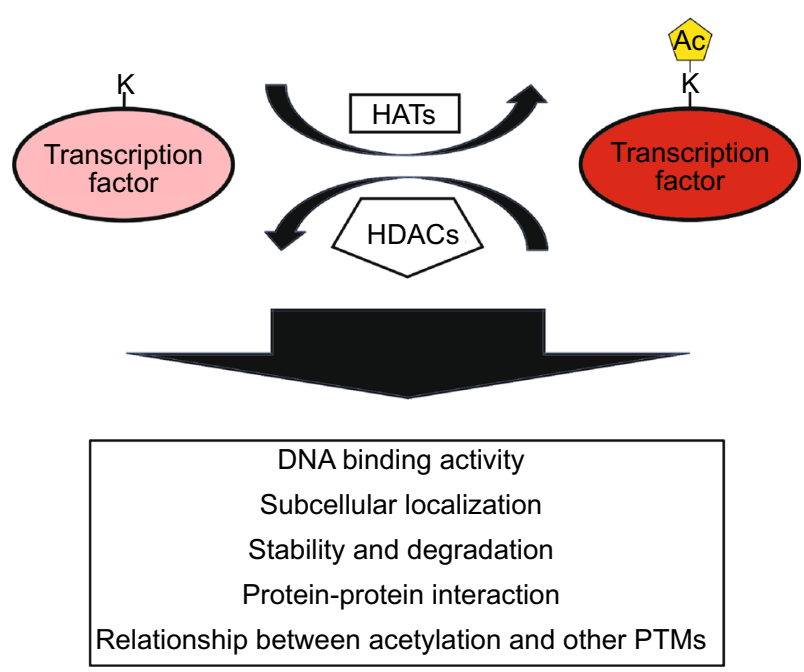

Figure 1. Functional consequences of acetylation of transcription factors. Ac, acetyl group; $\mathrm{K}$, lysine residue. phylogenetic analysis (Shirakawa et al., 2013). Class I HDACs constitute HDAC $1,-2,-3$, and -8 and are primarily localized to the nucleus. Class II HDACs include HDAC4, -5 , $-6,-7,-9$, and -10 and shuttle between nucleus and cytoplasm (Khan and La Thangue, 2012). Class III HDACs, termed sirtuins, act as NAD+-dependent deacetylases or ADP-ribosyltransferase (Imai and Guarente, 2014). There are seven sirtuins (SIRT1-7), which are distributed in the nucleus, cytoplasm, and/or mitochondria (Chang and Guarente, 2014; Imai and Guarente, 2014).

\section{Physiological role of HATs and HDACs in the regulation of metabolic processes}

Knockout of HATs/HDACs in mice generally results in embryonic lethality (Lagger et al., 2002; Rebel et al., 2002; Gorrini et al., 2007; Montgomery et al., 2008; Gabay et al., 2013). Consequently, studies on the physiological effects of HATs/HDACs require the creation of conditional Cre/LoxPknockout alleles and heterozygous mice. Among HATs, $\mathrm{CBP} / \mathrm{p} 300$ is a well-known player involved in regulation of glucose and lipid metabolism. The phenotypes of heterozygous CBP-deficient mice show increased insulin sensitivity and glucose tolerance despite prominent lipodystrophy of white adipose tissue (Yamauchi et al., 2002). Expression of a $\mathrm{CH} 1$ domain deletion mutant of CBP/p300 results in improvement of insulin sensitivity with reduction in white adipose tissue and body mass (Bedford et al., 2011). Additionally, disruption of $\mathrm{CBP} / \mathrm{p} 300$ using adenoviral short hairpin RNA (shRNA) leads to decreased hepatic glucose production (HGP), whereas overexpression of p300 impairs glucose homeostasis and insulin sensitivity (Bricambert et al., 2010; He et al., 2013). Mice with a glycine-to-serine mutation (G422S) of p300 exhibit decreased HGP, suggesting that phosphorylation at serine residues within p300 cause decreases in acetyltransferase activity (He et al., 2012; He et al., 2013). In the HDAC family, HDAC3 and SIRT1 have been well studied in association with metabolic homeostasis. SIRT1 heterozygous knockout mice fed a high-fat diet (HFD) show increased expression of lipogenic genes, and the mice exhibit increased risk of fatty liver development (Xu et al., 2010). Moreover, liver or adipose tissue-specific SIRT1-knockout mice exhibit increased body weight with development of metabolic dysfunction when fed an HFD (Purushotham et al., 2009; Chalkiadaki and Guarente, 2012). Conversely, the gain of SIRT1 function improves glucose homeostasis and insulin-sensitivity in diabetic mice models (Banks et al., 2008; Li et al., 2011). In contrast, liverspecific HDAC3-knockout mice show significant lipid accumulation resulting from increased triglycerides (TG) and overexpression of peroxisome proliferator-activated receptor gamma (PPARY) genes (Knutson et al., 2008). However, these mice show improved insulin sensitivity and lowered HGP when excess pyruvate and lactate are used for synthesis of TG (Sun et al., 2012). Also, suppression of class Ila 
Table 1. Summary of the physiological roles of HATs and HDACs

\begin{tabular}{lllc}
\hline $\begin{array}{l}\text { Acetylase/ } \\
\text { Deacetylase }\end{array}$ & $\begin{array}{l}\text { Loss/Gain of } \\
\text { function }\end{array}$ & Physiological roles & References \\
\hline CBP & Loss & Increased insulin sensitivity and glucose tolerance & Yamauchi et al. (2002) \\
CBP/p300 & Loss & $\begin{array}{l}\text { Improved insulin sensitivity with reduction in body mass } \\
\text { Decreased glucose production }\end{array}$ & $\begin{array}{c}\text { Bedford et al. (2011) } \\
\text { He et al. (2012) }\end{array}$ \\
P300 & Gain & Impaired insulin sensitivity and glucose tolerance & Bricambert et al. (2010) \\
SIRT1 & Loss & Impaired insulin sensitivity and glucose tolerance & Chalkiadaki and \\
& & Increased fatty liver development & Guarente (2012) \\
& Gain & Improved insulin sensitivity and glucose tolerance & Banks et al. (2008), Li \\
& & & et al. (2011) \\
HDAC3 & Loss & Improved insulin sensitivity and glucose tolerance, despite of & Sun et al. (2012) \\
increased lipid accumulation & Mihaylova et al. (2011) \\
\hline
\end{tabular}

HDACs (HDAC4, -5, and -7) ameliorates glucose homeostasis in mice with diet-induced obesity (DIO) mice due to inhibition of hepatic gluconeogenesis (Mihaylova et al., 2011). The physiological roles of HATs/HDACs are summarized in Table 1.

\section{ROLE OF TRANSCRIPTION FACTOR ACETYLATION IN THE REGULATION OF GLUCOSE AND LIPID METABOLISM}

\section{Forkhead box $\mathrm{O}$ (FoxO) family proteins}

Forkhead box $\mathrm{O}$ (FoxO) family proteins including FoxO1, $-3 a,-4$, and -6 are a subfamily of the forkhead group of transcription factors and play a pivotal role in energy metabolism in peripheral tissues (Eijkelenboom and Burgering, 2013). In particular, FOXO1 (also known as FKHR) is important for regulating genes of glucose and lipid metabolism (Matsumoto et al., 2007; Nakae et al., 2008). Phosphorylation of FOXO1 causes cytoplasmic localization resulting in inhibition of its transcriptional activities (Fig. 2) (Maiese et al., 2008). Recently, the transactivation of FOXO1 was shown to be regulated in response to growth factors, starvation, hypoxic stress, and oxidative stress (van der Horst and Burgering, 2007; Calnan and Brunet, 2008). Acetylation of FOXO1 occurs at three lysine residues (Lys242, Lys245, and Lys262) and is facilitated by HATs, such as CBP and p300 (Table 2) (Matsuzaki et al., 2005; van der Heide and Smidt, 2005). Interestingly, the consequences of acetylation of FOXO1 are similar to those of phosphorylation; acetylation of $\mathrm{FOXO1}$ by $\mathrm{CBP} / \mathrm{p} 300$ leads to reduced DNA-binding activity and translocation to the cytoplasm (Fig. 2) (Matsuzaki et al., 2005; Perrot and Rechler, 2005). Deacetylation of FOXO1 is mediated mainly by class II and III HDACs (Fig. 2) (Huang and Tindall, 2007). Upon exposure to stress stimuli, SIRT1 interacts with the LXXLL motif of FOXO1, resulting in retention in the nucleus and increased in
DNA-binding activity (Fig. 2A) (Frescas et al., 2005; Nakae et al., 2006). Deacetylated FOXO1 elevates the expression of gluconeogenic genes (Fig. 2A) (Park et al., 2010). Furthermore, expression of gene encoding glucokinase (GK), a key enzyme in glucose utilization, is regulated through interrelationship between SIRT1-deacetylated FOXO1 and hepatocyte nuclear factor 4alpha (HNF4a) (Fig. 2A) (Ganjam et al., 2009). Recruitment of HDAC3 (a class I of HDACs) by class Ila HDACs resulted in the deacetylation of FOXO1, which in turn upregulates the expression of gluconeogenic genes (Fig. 2A) (Mihaylova et al., 2011). Recently, SIRT2 has also been known to deacetylate FOXO1, resulting in decreased adipocyte size with improvement in whole-body insulin sensitivity (Fig. 2B) (Jing et al., 2007; Gross et al., 2009). In 3T3-L1 pre-adipocytes, the deacetylation of FOXO1 by SIRT2 acts as a critical modulator of FOXO1 activity, resulting in the transcriptional repression of the PPARY promoter (Fig. 2B) (Jing et al., 2007). In addition, administration of adenoviral SIRT2 shRNA increases the acetylation of FOXO1, alleviating the suppression of PPARY gene expression by inducing export of FOXO1 into the cytoplasm (Fig. 2B) (Jing et al., 2007; Wang and Tong, 2009).

\section{cAMP-responsive element-binding (CREB) protein}

CREB is a transcription factor that binds to an 8-bp element known as the cAMP-response element (CRE) in the promoter regions of target genes (Altarejos and Montminy, 2011). CREB is expressed in several tissues that regulate the expression of genes related to neuronal differentiation, adipocyte differentiation, hepatic glucose levels, and lipid metabolism (Altarejos and Montminy, 2011; Ravnskjaer et al., 2013). Suppressing CREB using antisense-oligonucleotides (ASOs) prevents hepatic insulin resistance and steatosis-associated T2DM (Erion et al., 2009). Phosphorylation of CREB by glucagon is well characterized and enhances transcriptional activities (Fig. 2A) (Altarejos and 
A
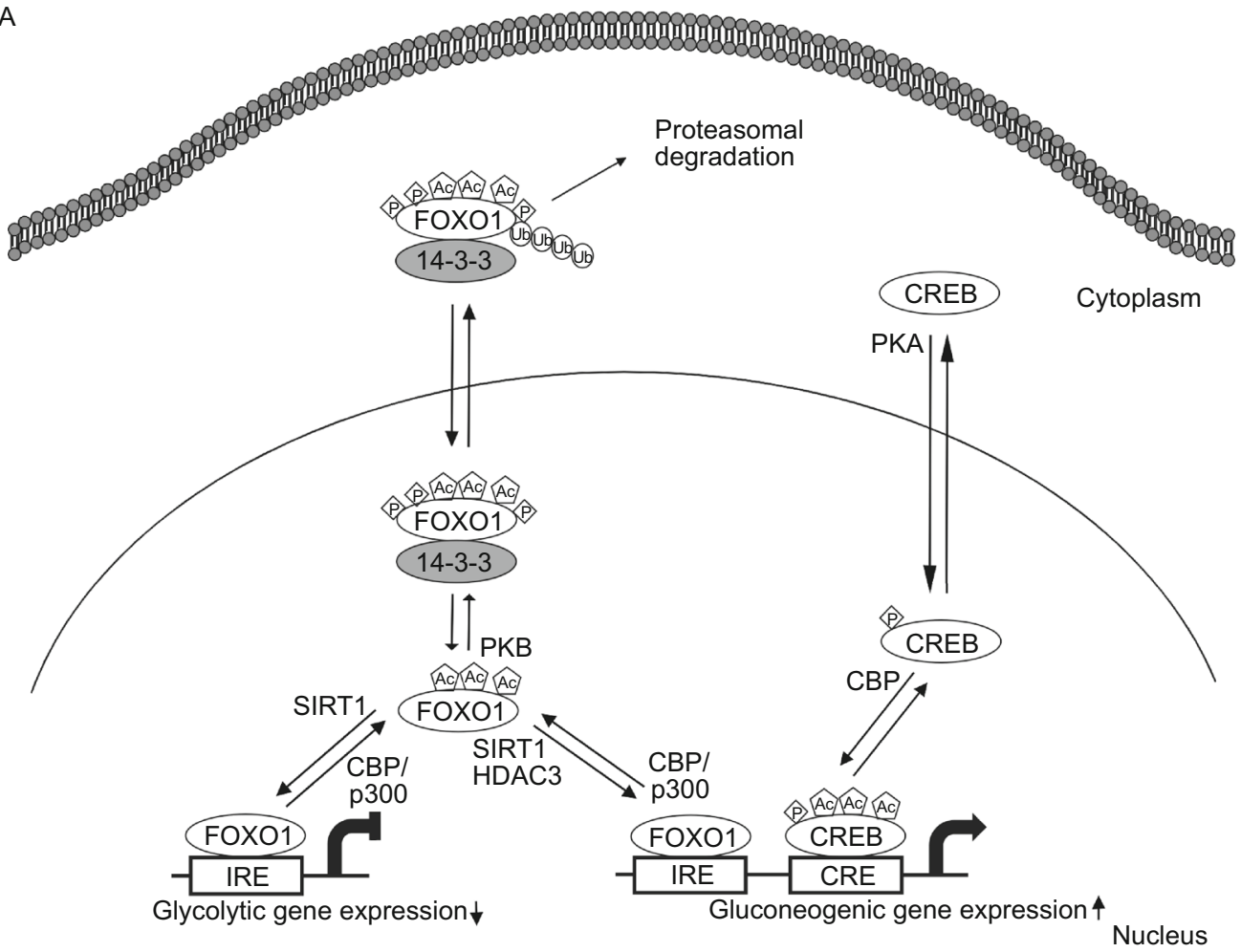

B

Figure 2. Role of transcription factor acetylation on the regulation of glucose. (A) Effect of FOXO1 and CREB acetylation on the carbohydrate metabolism. Acetylation of FOXO1 is balanced by SIRT1 and CBP/p300. Once acetylated, 14-3-3 binds to FOXO1, and localizes to cytosol. The 14-3-3FOXO1 complex is subjected to proteosomal degradation in cytosol. Deacetylated form of FOXO1 binds to IRE and transactivates glycolytic genes or gluconeogenic genes in a negative or a positive way, respectively. Acetylated form of CREB transactivates gluconeogenic gene expression by binding to $C R E$ in the gluconeogenic genes. Acetylation of CREB is promoted when CREB is phosphorylated. (B) Effect of transcription factor acetylation on the expression of lipogenic genes. Deacetylated form of FOXO1 downregulates adipogenic gene expression by binding to IRE of respective genes. FOXA2 is acetylated by $\mathrm{p} 300$ and upregulates expression of genes involved in $\beta$-oxidation and ketogenesis. Deacetylated form of FOXA2 is subjected to proteosomal degradation. SREBP family is also acetylated by CBP/p300. Acetylated form of SREBPs upregulates lipogeneic gene expression. Deacetylated form of SREBPs undergo proteasomal degradation. Acetylated form of ChREBP by p300 upregulates gene expression of lipogenic genes. Deacetylated form of ChREBP is phosphorylated by PKA, which promotes binding of 14-3-3, resulting in cytosolic localization. Acetylation of C/EBP $\beta$ is balanced by GCN5 and HDAC1. Acetyl-C/EBP $\beta$ upregulates adipogenic gene expression. Ac, acetyl group; $\mathrm{P}$, phosphorylation; Ub, ubiquitination; IRE, insulin-response element; CRE, cAMP-response element; PKA, protein kinase A; SRE, SREBP response element; PP2a, protein phosphatase 2a; CRM1, chromosome region maintenance 1 protein.

Montminy, 2011). CBP is known to acetylate three lysine residues (Lys91, Lys94, and Lys136) located within the activation domain of CREB (Table 2) (Lu et al., 2003). Moreover, acetylation of CREB increases CREB-dependent transactivation (Fig. 2A) (Lu et al., 2003). Interestingly, the function of CREB in glucose and lipid metabolism has been suggested to be regulated by the crosstalk between acetylation and phosphorylation (Fig. 2A) (Paz et al., 2014).

\section{Sterol response element-binding proteins (SREBPs)}

SREBPs are transcriptional regulators belonging to the basic helix-loop-helix leucine zipper (bHLH/LZ) family (Soyal et al., 2015). The SREBP family consists of SREBP-1a, -1c, and -2 (Shimano, 2009). SREBP-1c is primarily involved in fatty acid and TG biosynthesis, whereas SREBP-2 activates cholesterol biosynthesis (Soyal et al., 2015). In the feeding state, SREBP-1c stimulates both hepatic lipogenesis and glycolysis by upregulating target gene expression (Kim et al., 2004; Jeon and Osborne, 2012). One of the novel mechanisms regulating the transcriptional activities of SREBPs is PTMs, such as phosphorylation, ubiquitination, and acetylation (Fig. 2B) (Shao and Espenshade, 2012). In particular, acetylation has been shown to play a critical role in the regulation of SREBP transcriptional activity. SREBPs are acetylated by $\mathrm{CBP} / \mathrm{p} 300$ through direct interactions (Giandomenico et al., 2003; Sundqvist and Ericsson, 2003). There are three potential acetylation sites in SREBP-1a (Lys313, Lys324, and Lys333) (Table 2) (Giandomenico et al., 2003). Among these, two lysine residues (Lys324 and Lys333) located at DNA-binding domain are important for transcriptional activation (Fig. 2B) (Giandomenico et al., 2003). Indeed, CBP/p300 plays a critical role in the regulation of SREBP-1a stability by interfering with the ubiquitination of these residues (Fig. 2B) (Giandomenico et al., 2003; Sundqvist and Ericsson, 2003). In contrast, SREBP-1a is deacetylated by SIRT1, resulting in a decrease in the stability and its association with hepatic lipogenic gene expression (Fig. 2B) (Walker et al., 2010). In parallel with SREBP-1a, acetylation and deacetylation of SREBP-1c occurs at Lys289 and Lys309 through the activity of p300 and SIRT1, respectively (Fig. 2B; Table 2) (Ponugoti et al., 2010). Notably, the acetylation of SREBP-1c is highly increased in DIO mice and depletion of hepatic SIRT1 in mice results in increased lipogenic gene expression (Ponugoti et al., 2010). In addition, overexpression of SIRT1 attenuates the transcriptional activity of SREBP-1c by decreasing stability and occupancy at the promoter of lipogenic genes (Fig. 2B) (Ponugoti et al., 2010). In a

Table 2. List of acetylated transcription factors that are involved in glucose and lipid metabolism

\begin{tabular}{lllll}
\hline Transcription factor & Acetylase & Deacetylase & Amino acid & References \\
\hline FOXO1 & CBP/p300 & $\begin{array}{l}\text { SIRT1 } \\
\text { SIRT2 }\end{array}$ & K242, K245, K262 & Matsuzaki et al. (2005), Jing et al. (2007) \\
CREB & CBP/p300 & SIRT1 & K91, K94, K136 & Lu et al. (2003), Paz et al. (2014) \\
SREBP-1a & CBP/p300 & & K313, K324, K333 & Giandomenico et al. (2003) \\
SREBP-1c & p300 & SIRT1 & K289, K309 & Ponugoti et al. (2010) \\
SREBP-2 & CBP/p300 & & & Giandomenico et al. (2003) \\
FOXA2 & p300 & SIRT1 & K259, K275 & von Meyenn et al. (2013) \\
ChREBP & p300 & SIRT1 & K672 & Bricambert et al. (2010), Marmier et al. (2015) \\
C/EBP 3 & GCN5 & HDAC1 & K39, K98, K101, K102 & Cesena et al. (2007), Wiper-Bergeron et al. \\
& & & & (2007), Cesena et al. (2008) \\
\hline
\end{tabular}


physiological state, reversible acetylation of SREBPs is dynamically regulated during fasting and feeding cycles (Walker et al., 2010). Function of acetylated SREBP-2 and its acetylation sites are not identified despite SREBP-2 is acetylated by CBP/p300 (Giandomenico et al., 2003). It may be possible that acetylation of SREBP-2 may have similar biological consequnences which observed in the acetylation of other subtypes SREBPs.

\section{Forkhead box $\mathrm{A}$ (FoxA) family proteins}

FoxA family proteins, including FoxA1, -A2, and -A3 (also known as HNF3a, HNF3 $\beta$, and HNF3y) belong to a subfamily of the forkhead group containing a winged helix DNAbinding domain and play a crucial role in lipid metabolism (Lalmansingh et al., 2012). FOXA2 is a central regulator in hepatic lipid metabolism, with role in fatty acid oxidation, ketogenesis, and bile acid metabolism (Wolfrum et al., 2004). Interestingly, phosphorylation of FOXA2 by metabolic stress causes nuclear export with inhibition of its transcriptional activities (Fig. 2B) (Howell and Stoffel, 2009; Banerjee et al., 2010). Acetylation of FOXA2 occurs at multiple lysine residues (Lys6, Lys259, Lys264, Lys274, and Lys275) (Table 2) (van Gent et al., 2014). Among these, two residues (Lys259 and Lys275) are acetylated by $\mathrm{p} 300$ when glucagon is added (von Meyenn et al., 2013). In contrast to phosphorylation, acetylation of FOXA2 results in increased in their stability and transcriptional activity due to retention in the nucleus (Fig. 2B) (von Meyenn et al., 2013; van Gent et al., 2014). As expected, deacetylation of FOXA2 by SIRT1 has the opposite effects, causing reductions in stability and transactivation in the nucleus (Fig. 2B) (von Meyenn et al., 2013; van Gent et al., 2014). Overall, acetylation of FOXA2 may prevent the T2DM by upregulating the expression of $\beta$-oxidation and ketogenesis (Wolfrum et al., 2004; von Meyenn et al., 2013).

\section{Carbohydrate-response element-binding protein (ChREBP)}

ChREBP is a $b H L H / L Z$ transcription factor that functions in forming a heterodimeric complex with Max-like protein $X$ (MLX) (Ma et al., 2006). ChREBP is a major mediator of the glucose effect independent of insulin action, which upregulates glycolysis- and lipogenesis-related genes, such as L-pyruvate kinase (L-PK), fatty acid synthase (FAS), acetylCoA carboxylase (ACC), and steroyl-CoA desaturase-1 (SCD-1) (Postic et al., 2007). The transcriptional activities of ChREBP are regulated by multiple PTMs, including phosphorylation, O-GIcNAcylation, and acetylation (Guinez et al., 2011; Filhoulaud et al., 2013). In the high-glucose state, ChREBP is acetylated by $\mathrm{p} 300$ at Lys672, which is located within the bHLH/LZ domain (Table 2) (Bricambert et al., 2010; Chen et al., 2010). In contrast to the other transcription factors mentioned above, acetylation of ChREBP does not affect nuclear-cytoplasmic shuttling (Fig. 2B) (Bricambert et al., 2010). Acetylated ChREBP readily binds to the ChREBP-responsive element (ChoRE) (Fig. 2B) (Bricambert et al., 2010). Recently, acetylation of ChREBP is increased by inhibiting the expression and activity of SIRT1 upon ethanol (EtOH) treatment (Fig. 2B) (Marmier et al., 2015). Consequently, hyper-acetylated ChREBP increases the expression of lipogenesis-related genes in the liver.

\section{CCAAT/enhancer-binding proteins (C/EBPs)}

There are six members in C/EBP family (Nerlov, 2007). These proteins are bZIP transcription factors and are expressed in peripheral tissues (Nerlov, 2007). Among these, C/EBP $\beta$ plays an important role in hepatic glucose and lipid metabolism (Schrem et al., 2004). Modulation of transcriptional activities by C/EBP $\beta$ phosphorylation has been demonstrated (Park et al., 2004). Acetylation of C/EBP $\beta$ may also serve as a molecular switch for the regulation of transcription activities (Cesena et al., 2007; WiperBergeron et al., 2007; Cesena et al., 2008). Acetylation of $\mathrm{C} / \mathrm{EBP} \beta$ at Lys39, which is located within the activation domain (AD), results in the transactivation of gene expression associated with adipogenesis (Fig. 2B; Table 2) (Cesena et al., 2007; Cesena et al., 2008). In glucocorticoidstimulated pre-adipocyte differentiation, GCN5 is known to acetylate lysine residues (Lys98, Lys101, and Lys102) (Fig. 2B; Table 2) (Wiper-Bergeron et al., 2007). Acetylation of $\mathrm{C} / \mathrm{EBP} \beta$ increases the transcription of $\mathrm{C} / \mathrm{EBP} \beta$ target genes, such as C/EBPa and PPARy by disrupting the interaction between $\mathrm{C} / \mathrm{EBP} \beta$ and the HDAC1 corepressor complex (Fig. 2B) (Abdou et al., 2011). At present, deacetylation of C/EBP $\beta$ and its biological significance are not clear. It is possible that deacetylation of C/EBP $\beta$ may have opposing effects to acetylation, similar to the phenomena observed for other transcription factors.

\section{PERSPECTIVES AND CONCLUSION}

The epidemic of metabolic syndrome and T2DM has become a serious health problem in modern society. In the coming decades, these disorders will cause a much larger global problem, requiring physical, social, and economic expenses. In this review, we have summarized recent advancements in the understanding of gene regulation in the context of reversible acetylation/deacetylation of transcription factors and their roles in the regulation of gene involved in metabolic homeostasis, which are associated with the pathogenesis of metabolic syndrome. It has become clear that single or multiple acetylation residue(s) in transcription factors can trigger significant effects on whole-body energy homeostasis.

Exploring the key features of non-histone protein acetylation, including that of transcription factors will be critical for understanding fine control of whole body metabolism. Thus understanding the molecular mechanisms and physiological relevance of acetylation is of great interest, considering the 
therapeutic potential of these processes in the development of drugs combating metabolic syndrome and T2DM.

\section{ACKNOWLEDGEMENTS}

We would like to apologize to all contributors to this field whose work could not be cited here due to space limitations. The publication of this review was supported by the Basic Science Research Program through the National Research Foundation of Korea (NRF) and funded by the Ministry of Education, Science and Technology (NRF2011-0030086 and 2014R1A2A2A01004396 to YHA, NRF2013R1A1A2058302 to JMP).

\section{ABBREVIATIONS}

ACC, acetyl-CoA carboxylase; bHLH/LZ, basic helix-loop-helix leucine zipper; CBP, cAMP-response element-binding protein-binding protein; C/EBPs, CCAAT/enhancer-binding proteins; ChREBP, carbohydrate-response element-binding protein; CREB, cAMP-responsive element-binding; DIO, diet-induced obesity; $\mathrm{EtOH}$, ethanol; FAS, fatty acid synthase; FoxA, forkhead box A; FoxO, forkhead box $\mathrm{O}$; GK, glucokianse; GNATs, Gcn5-related N-acetyltransferases; HATs, histone acetyltransferases; HFD, high-fat diet; HGP, hepatic glucose production; HNF4a, hepatocyte nuclear factor 4alpha; MLX, Max-like protein X; L-PK, L-pyruvate kinase; p300, E1A-associated protein of $300 \mathrm{kDa}$; PHDACs, histone deacetylaes; PPARy, peroxisome proliferator-activated receptor gamma; SCD-1, steroyl-CoA desaturase-1; SIRTs, sirtuins; SREBPs, sterol response elementbinding proteins; T2DM, type 2 diabetes mellitus; TG, triglycerides; TMs, post-translational modifications.

\section{COMPLIANCE WITH ETHICS GUIDELINES}

Joo-Man Park, Seong-Ho Jo, Mi-Young Kim, Tae-Hyun Kim and Yong-Ho Ahn declare that they have no conflict of interest. This article does not contain any studies with human or animal subjects performed by the any of the authors.

\section{OPEN ACCESS}

This article is distributed under the terms of the Creative Commons Attribution 4.0 International License (http://creativecommons.org/ licenses/by/4.0/), which permits unrestricted use, distribution, and reproduction in any medium, provided you give appropriate credit to the original author(s) and the source, provide a link to the Creative Commons license, and indicate if changes were made.

\section{REFERENCES}

Abdou HS, Atlas E, Hache RJ (2011) Liver-enriched inhibitory protein (LIP) actively inhibits preadipocyte differentiation through histone deacetylase 1 (HDAC1). J Biol Chem 286:21488-21499 Allis CD, Berger SL, Cote J, Dent S, Jenuwien T, Kouzarides T, Pillus L, Reinberg D, Shi Y, Shiekhattar R, Shilatifard A, Workman J, Zhang $Y$ (2007) New nomenclature for chromatin-modifying enzymes. Cell 131:633-636
Altarejos JY, Montminy M (2011) CREB and the CRTC co-activators: sensors for hormonal and metabolic signals. Nat Rev Mol Cell Biol 12:141-151

Banerjee A, Meyer K, Mazumdar B, Ray RB, Ray R (2010) Hepatitis $C$ virus differentially modulates activation of forkhead transcription factors and insulin-induced metabolic gene expression. J Virol 84:5936-5946

Banks AS, Kon N, Knight C, Matsumoto M, Gutierrez-Juarez R, Rossetti L, Gu W, Accili D (2008) SirT1 gain of function increases energy efficiency and prevents diabetes in mice. Cell Metab 8:333-341

Bedford DC, Kasper LH, Wang R, Chang Y, Green DR, Brindle PK (2011) Disrupting the $\mathrm{CH} 1$ domain structure in the acetyltransferase $\mathrm{CBP}$ and p300 results in lean mice with increased metabolic control. Cell Metab 14:219-230

Bricambert J, Miranda J, Benhamed F, Girard J, Postic C, Dentin R (2010) Salt-inducible kinase 2 links transcriptional coactivator p300 phosphorylation to the prevention of ChREBP-dependent hepatic steatosis in mice. J Clin Invest 120:4316-4331

Calnan DR, Brunet A (2008) The FoxO code. Oncogene 27:22762288

Carrozza MJ, Utley RT, Workman JL, Cote J (2003) The diverse functions of histone acetyltransferase complexes. Trends Genet 19:321-329

Cesena TI, Cardinaux JR, Kwok R, Schwartz J (2007) CCAAT/ enhancer-binding protein (C/EBP) beta is acetylated at multiple lysines: acetylation of C/EBPbeta at lysine 39 modulates its ability to activate transcription. J Biol Chem 282:956-967

Cesena TI, Cui TX, Subramanian L, Fulton CT, Iniguez-Lluhi JA, Kwok RP, Schwartz J (2008) Acetylation and deacetylation regulate CCAAT/enhancer binding protein beta at K39 in mediating gene transcription. Mol Cell Endocrinol 289:94-101

Chalkiadaki A, Guarente L (2012) High-fat diet triggers inflammationinduced cleavage of SIRT1 in adipose tissue to promote metabolic dysfunction. Cell Metab 16:180-188

Chang HC, Guarente L (2014) SIRT1 and other sirtuins in metabolism. Trends Endocrinol Metab 25:138-145

Chen S, Feng B, George B, Chakrabarti R, Chen M, Chakrabarti S (2010) Transcriptional coactivator p300 regulates glucose-induced gene expression in endothelial cells. Am J Physiol Endocrinol Metab 298:E127-137

Chen L, Magliano DJ, Zimmet PZ (2012) The worldwide epidemiology of type 2 diabetes mellitus-present and future perspectives. Nat Rev Endocrinol 8:228-236

Choudhary C, Weinert BT, Nishida Y, Verdin E, Mann M (2014) The growing landscape of lysine acetylation links metabolism and cell signalling. Nat Rev Mol Cell Biol 15:536-550

Eijkelenboom A, Burgering BM (2013) FOXOs: signalling integrators for homeostasis maintenance. Nat Rev Mol Cell Biol 14: 83-97

Erion DM, Ignatova ID, Yonemitsu S, Nagai Y, Chatterjee P, Weismann D, Hsiao JJ, Zhang D, Iwasaki T, Stark R, Flannery C, Kahn M, Carmean CM, Yu XX, Murray SF, Bhanot S, Monia BP, Cline GW, Samuel VT, Shulman GI (2009) Prevention of hepatic steatosis and hepatic insulin resistance by knockdown of cAMP response element-binding protein. Cell Metab 10: 499-506 
Filhoulaud G, Guilmeau S, Dentin R, Girard J, Postic C (2013) Novel insights into ChREBP regulation and function. Trends Endocrinol Metab 24:257-268

Francis GA, Fayard E, Picard F, Auwerx J (2003) Nuclear receptors and the control of metabolism. Annu Rev Physiol 65:261-311

Frescas D, Valenti L, Accili D (2005) Nuclear trapping of the forkhead transcription factor FoxO1 via Sirt-dependent deacetylation promotes expression of glucogenetic genes. J Biol Chem 280:20589-20595

Gabay O, Zaal KJ, Sanchez C, Dvir-Ginzberg M, Gagarina V, Song Y, He XH, McBurney MW (2013) Sirt1-deficient mice exhibit an altered cartilage phenotype. Joint Bone Spine 80:613-620

Ganjam GK, Dimova EY, Unterman TG, Kietzmann T (2009) FoxO1 and HNF-4 are involved in regulation of hepatic glucokinase gene expression by resveratrol. J Biol Chem 284:30783-30797

Giandomenico V, Simonsson M, Gronroos E, Ericsson J (2003) Coactivator-dependent acetylation stabilizes members of the SREBP family of transcription factors. Mol Cell Biol 23:25872599

Glozak MA, Sengupta N, Zhang X, Seto E (2005) Acetylation and deacetylation of non-histone proteins. Gene 363:15-23

Gorrini C, Squatrito M, Luise C, Syed N, Perna D, Wark L, Martinato F, Sardella D, Verrecchia A, Bennett S, Confalonieri S, Cesaroni M, Marchesi F, Gasco M, Scanziani E, Capra M, Mai S, Nuciforo P, Crook T, Lough J, Amati B (2007) Tip60 is a haplo-insufficient tumour suppressor required for an oncogene-induced DNA damage response. Nature 448:1063-1067

Gross DN, Wan M, Birnbaum MJ (2009) The role of FOXO in the regulation of metabolism. Curr Diab Rep 9:208-214

Guan KL, Xiong Y (2011) Regulation of intermediary metabolism by protein acetylation. Trends Biochem Sci 36:108-116

Guinez C, Filhoulaud G, Rayah-Benhamed F, Marmier S, Dubuquoy C, Dentin R, Moldes M, Burnol AF, Yang X, Lefebvre T, Girard J, Postic C (2011) O-GlcNAcylation increases ChREBP protein content and transcriptional activity in the liver. Diabetes 60:13991413

Haigis MC, Sinclair DA (2010) Mammalian sirtuins: biological insights and disease relevance. Annu Rev Pathol 5:253-295

He L, Naik K, Meng S, Cao J, Sidhaye AR, Ma A, Radovick S, Wondisford FE (2012) Transcriptional co-activator p300 maintains basal hepatic gluconeogenesis. J Biol Chem 287:3206932077

He L, Cao J, Meng S, Ma A, Radovick S, Wondisford FE (2013) Activation of basal gluconeogenesis by coactivator p300 maintains hepatic glycogen storage. Mol Endocrinol 27:13221332

Howell JJ, Stoffel M (2009) Nuclear export-independent inhibition of Foxa2 by insulin. J Biol Chem 284:24816-24824

Huang H, Tindall DJ (2007) Dynamic FoxO transcription factors. J Cell Sci 120:2479-2487

Imai S, Guarente L (2014) NAD+ and sirtuins in aging and disease. Trends Cell Biol 24:464-471

Jeon TI, Osborne TF (2012) SREBPs: metabolic integrators in physiology and metabolism. Trends Endocrinol Metab 23:65-72

Jing E, Gesta S, Kahn CR (2007) SIRT2 regulates adipocyte differentiation through FoxO1 acetylation/deacetylation. Cell Metab 6:105-114
Kahn SE, Hull RL, Utzschneider KM (2006) Mechanisms linking obesity to insulin resistance and type 2 diabetes. Nature 444:840-846

Khan O, La Thangue NB (2012) HDAC inhibitors in cancer biology: emerging mechanisms and clinical applications. Immunol Cell Biol 90:85-94

Kim SY, Kim HI, Kim TH, Im SS, Park SK, Lee IK, Kim KS, Ahn YH (2004) SREBP-1c mediates the insulin-dependent hepatic glucokinase expression. J Biol Chem 279:30823-30829

Kim SC, Sprung R, Chen Y, Xu Y, Ball H, Pei J, Cheng T, Kho Y, Xiao H, Xiao L, Grishin NV, White M, Yang XJ, Zhao Y (2006) Substrate and functional diversity of lysine acetylation revealed by a proteomics survey. Mol Cell 23:607-618

Kimura A, Matsubara K, Horikoshi M (2005) A decade of histone acetylation: marking eukaryotic chromosomes with specific codes. J Biochem 138:647-662

Knutson SK, Chyla BJ, Amann JM, Bhaskara S, Huppert SS, Hiebert SW (2008) Liver-specific deletion of histone deacetylase 3 disrupts metabolic transcriptional networks. EMBO J 27:10171028

Lagger G, O'Carroll D, Rembold M, Khier H, Tischler J, Weitzer G, Schuettengruber B, Hauser C, Brunmeir R, Jenuwein T, Seiser C (2002) Essential function of histone deacetylase 1 in proliferation control and CDK inhibitor repression. EMBO J 21:2672-2681

Lalmansingh AS, Karmakar S, Jin Y, Nagaich AK (2012) Multiple modes of chromatin remodeling by Forkhead box proteins. Biochim Biophys Acta 1819:707-715

Lee KK, Workman JL (2007) Histone acetyltransferase complexes: one size doesn't fit all. Nat Rev Mol Cell Biol 8:284-295

Li Y, Xu S, Giles A, Nakamura K, Lee JW, Hou X, Donmez G, Li J, Luo Z, Walsh K, Guarente L, Zang M (2011) Hepatic overexpression of SIRT1 in mice attenuates endoplasmic reticulum stress and insulin resistance in the liver. FASEB J 25:1664-1679

Li Y, Varala K, Coruzzi GM (2015) From milliseconds to lifetimes: tracking the dynamic behavior of transcription factors in gene networks. Trends Genet. doi:10.1016/j.tig.2015.05.005

Lu Q, Hutchins AE, Doyle CM, Lundblad JR, Kwok RP (2003) Acetylation of cAMP-responsive element-binding protein (CREB) by CREB-binding protein enhances CREB-dependent transcription. J Biol Chem 278:15727-15734

Ma L, Robinson LN, Towle HC (2006) ChREBP*Mlx is the principal mediator of glucose-induced gene expression in the liver. J Biol Chem 281:28721-28730

Maiese K, Chong ZZ, Shang YC (2008) OutFOXOing disease and disability: the therapeutic potential of targeting FoxO proteins. Trends Mol Med 14:219-227

Marmier S, Dentin R, Daujat-Chavanieu M, Guillou H, BertrandMichel J, Gerbal-Chaloin S, Girard J, Lotersztajn S, Postic C (2015) Novel role for carbohydrate responsive element binding protein in the control of ethanol metabolism and susceptibility to binge drinking. Hepatology. doi:10.1002/hep.27778

Matsumoto M, Pocai A, Rossetti L, Depinho RA, Accili D (2007) Impaired regulation of hepatic glucose production in mice lacking the forkhead transcription factor Foxo1 in liver. Cell Metab 6:208216

Matsuzaki H, Daitoku H, Hatta M, Aoyama H, Yoshimochi K, Fukamizu A (2005) Acetylation of Foxo1 alters its DNA-binding 
ability and sensitivity to phosphorylation. Proc Natl Acad Sci U S A 102:11278-11283

Meek DW, Anderson CW (2009) Posttranslational modification of p53: cooperative integrators of function. Cold Spring Harb Perspect Biol 1:a000950

Mihaylova MM, Vasquez DS, Ravnskjaer K, Denechaud PD, Yu RT, Alvarez JG, Downes M, Evans RM, Montminy M, Shaw RJ (2011) Class lla histone deacetylases are hormone-activated regulators of FOXO and mammalian glucose homeostasis. Cell 145:607621

Montgomery RL, Potthoff MJ, Haberland M, Qi X, Matsuzaki S, Humphries KM, Richardson JA, Bassel-Duby R, Olson EN (2008) Maintenance of cardiac energy metabolism by histone deacetylase 3 in mice. J Clin Invest 118:3588-3597

Nakae J, Cao Y, Daitoku H, Fukamizu A, Ogawa W, Yano Y, Hayashi $Y(2006)$ The LXXLL motif of murine forkhead transcription factor FoxO1 mediates Sirt1-dependent transcriptional activity. J Clin Invest 116:2473-2483

Nakae J, Cao Y, Oki M, Orba Y, Sawa H, Kiyonari H, Iskandar K, Suga K, Lombes M, Hayashi $Y$ (2008) Forkhead transcription factor FoxO1 in adipose tissue regulates energy storage and expenditure. Diabetes 57:563-576

Nerlov C (2007) The C/EBP family of transcription factors: a paradigm for interaction between gene expression and proliferation control. Trends Cell Biol 17:318-324

Nerlov C (2008) C/EBPs: recipients of extracellular signals through proteome modulation. Curr Opin Cell Biol 20:180-185

Park BH, Qiang L, Farmer SR (2004) Phosphorylation of C/EBPbeta at a consensus extracellular signal-regulated kinase/glycogen synthase kinase 3 site is required for the induction of adiponectin gene expression during the differentiation of mouse fibroblasts into adipocytes. Mol Cell Biol 24:8671-8680

Park JM, Kim TH, Bae JS, Kim MY, Kim KS, Ahn YH (2010) Role of resveratrol in FOXO1-mediated gluconeogenic gene expression in the liver. Biochem Biophys Res Commun 403:329-334

Paz JC, Park S, Phillips N, Matsumura S, Tsai WW, Kasper L, Brindle PK, Zhang G, Zhou MM, Wright PE, Montminy M (2014) Combinatorial regulation of a signal-dependent activator by phosphorylation and acetylation. Proc Natl Acad Sci U S A 111:17116-17121

Perrot V, Rechler MM (2005) The coactivator p300 directly acetylates the forkhead transcription factor Foxo1 and stimulates Foxo1-induced transcription. Mol Endocrinol 19:2283-2298

Perry RJ, Samuel VT, Petersen KF, Shulman GI (2014) The role of hepatic lipids in hepatic insulin resistance and type 2 diabetes. Nature 510:84-91

Ponugoti B, Kim DH, Xiao Z, Smith Z, Miao J, Zang M, Wu SY, Chiang CM, Veenstra TD, Kemper JK (2010) SIRT1 deacetylates and inhibits SREBP-1C activity in regulation of hepatic lipid metabolism. J Biol Chem 285:33959-33970

Postic C, Dentin R, Denechaud PD, Girard J (2007) ChREBP, a transcriptional regulator of glucose and lipid metabolism. Annu Rev Nutr 27:179-192

Purushotham A, Schug TT, Xu Q, Surapureddi S, Guo X, Li X (2009) Hepatocyte-specific deletion of SIRT1 alters fatty acid metabolism and results in hepatic steatosis and inflammation. Cell Metab 9:327-338
Ravnskjaer K, Hogan MF, Lackey D, Tora L, Dent SY, Olefsky J, Montminy M (2013) Glucagon regulates gluconeogenesis through KAT2B- and WDR5-mediated epigenetic effects. J Clin Invest 123:4318-4328

Rebel VI, Kung AL, Tanner EA, Yang H, Bronson RT, Livingston DM (2002) Distinct roles for CREB-binding protein and p300 in hematopoietic stem cell self-renewal. Proc Natl Acad Sci U S A 99:14789-14794

Schrem H, Klempnauer J, Borlak J (2004) Liver-enriched transcription factors in liver function and development. Part II: the C/EBPs and $\mathrm{D}$ site-binding protein in cell cycle control, carcinogenesis, circadian gene regulation, liver regeneration, apoptosis, and liverspecific gene regulation. Pharmacol Rev 56:291-330

Shao W, Espenshade PJ (2012) Expanding roles for SREBP in metabolism. Cell Metab 16:414-419

Shimano H (2009) SREBPs: physiology and pathophysiology of the SREBP family. FEBS J 276:616-621

Shirakawa K, Chavez L, Hakre S, Calvanese V, Verdin E (2013) Reactivation of latent HIV by histone deacetylase inhibitors. Trends Microbiol 21:277-285

Soyal SM, Nofziger C, Dossena S, Paulmichl M, Patsch W (2015) Targeting SREBPs for treatment of the metabolic syndrome. Trends Pharmacol Sci 36:406-416

Sun Z, Miller RA, Patel RT, Chen J, Dhir R, Wang H, Zhang D, Graham MJ, Unterman TG, Shulman GI, Sztalryd C, Bennett MJ, Ahima RS, Birnbaum MJ, Lazar MA (2012) Hepatic Hdac3 promotes gluconeogenesis by repressing lipid synthesis and sequestration. Nat Med 18:934-942

Sundqvist A, Ericsson J (2003) Transcription-dependent degradation controls the stability of the SREBP family of transcription factors. Proc Natl Acad Sci U S A 100:13833-13838

Vahid F, Zand H, Nosrat-Mirshekarlou E, Najafi R, Hekmatdoost A (2015) The role dietary of bioactive compounds on the regulation of histone acetylases and deacetylases: a review. Gene 562:8-15 van der Heide LP, Smidt MP (2005) Regulation of FoxO activity by CBP/p300-mediated acetylation. Trends Biochem Sci 30:81-86

van der Horst A, Burgering BM (2007) Stressing the role of FoxO proteins in lifespan and disease. Nat Rev Mol Cell Biol 8:440-450 van Gent R, Di Sanza C, van den Broek NJ, Fleskens V, Veenstra A, Stout GJ, Brenkman AB (2014) SIRT1 mediates FOXA2 breakdown by deacetylation in a nutrient-dependent manner. PLoS One 9:e98438

von Meyenn F, Porstmann T, Gasser E, Selevsek N, Schmidt A, Aebersold R, Stoffel M (2013) Glucagon-induced acetylation of Foxa2 regulates hepatic lipid metabolism. Cell Metab 17:436447

Walker AK, Yang F, Jiang K, Ji JY, Watts JL, Purushotham A, Boss $\mathrm{O}$, Hirsch ML, Ribich S, Smith JJ, Israelian K, Westphal $\mathrm{CH}$, Rodgers JT, Shioda T, Elson SL, Mulligan P, Najafi-Shoushtari $H$, Black JC, Thakur JK, Kadyk LC, Whetstine JR, Mostoslavsky R, Puigserver P, Li X, Dyson NJ, Hart AC, Naar AM (2010) Conserved role of SIRT1 orthologs in fasting-dependent inhibition of the lipid/cholesterol regulator SREBP. Genes Dev 24:14031417

Wang F, Tong Q (2009) SIRT2 suppresses adipocyte differentiation by deacetylating FOXO1 and enhancing FOXO1's repressive interaction with PPARgamma. Mol Biol Cell 20:801-808 
Wang C, Tian L, Popov VM, Pestell RG (2011) Acetylation and nuclear receptor action. J Steroid Biochem Mol Biol 123:91-100

Wiper-Bergeron N, Salem HA, Tomlinson JJ, Wu D, Hache RJ (2007) Glucocorticoid-stimulated preadipocyte differentiation is mediated through acetylation of C/EBPbeta by GCN5. Proc Natl Acad Sci U S A 104:2703-2708

Wolfrum C, Asilmaz E, Luca E, Friedman JM, Stoffel M (2004) Foxa2 regulates lipid metabolism and ketogenesis in the liver during fasting and in diabetes. Nature 432:1027-1032

Xu F, Gao Z, Zhang J, Rivera CA, Yin J, Weng J, Ye J (2010) Lack of SIRT1 (Mammalian Sirtuin 1) activity leads to liver steatosis in the SIRT1+/- mice: a role of lipid mobilization and inflammation. Endocrinology 151:2504-2514
Yamauchi T, Oike Y, Kamon J, Waki H, Komeda K, Tsuchida A, Date Y, Li MX, Miki H, Akanuma Y, Nagai R, Kimura S, Saheki T, Nakazato M, Naitoh T, Yamamura K, Kadowaki T (2002) Increased insulin sensitivity despite lipodystrophy in Crebbp heterozygous mice. Nat Genet 30:221-226

Zhao Y, Wang Y, Zhu WG (2011) Applications of post-translational modifications of FoxO family proteins in biological functions. J Mol Cell Biol 3:276-282

Zivkovic AM, German JB, Sanyal AJ (2007) Comparative review of diets for the metabolic syndrome: implications for nonalcoholic fatty liver disease. Am J Clin Nutr 86:285-300 